\title{
3D SOLARWEB: A SOLAR CADASTER IN THE ITALIAN ALPINE LANDSCAPE
}

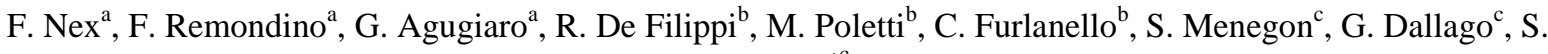 \\ Fontanari $^{\mathrm{c}}$
}

a 3D Optical Metrology (3DOM) unit

Bruno Kessler Foundation (FBK), Trento, Italy

Email: (franex, remondino, agugiaro)@fbk.eu, Web: http://3dom.fbk.eu

${ }^{\mathrm{b}}$ Predictive Models for Biomedicine \& Environment (MBPA) unit

Bruno Kessler Foundation (FBK), Trento, Italy

Email: (poletti, defilippi, furlan)@fbk.eu, Web: http://mpba.fbk.eu

${ }^{\mathrm{c}}$ MPASolutions, Trento, Italy

Email: (menegon, dallago, fontanari)@ mpasol.it, Web: http://www.mpasol.it

Paper submitted to the ISPRS Conference "Serving Society with Geoinformatics" (ISPRS2013-SSG)

KEY WORDS: Photogrammetry, DSM, WebGIS, Decision Support, Spatial Infrastructures, Photovoltaic

\begin{abstract}
:
The paper presents the research carried out in the on-going 3DSolarWeb project to test and implement a complete pipeline for the generation of a solar cadastre of building roofs located in alpine areas. The project aims at providing reliable results in a costeffective way, using (low resolution) available data and new aerial imagery acquisitions as input. The environmental context is digitally represented using already existing low resolution LiDAR data (1-2 m resolution), while the urban area is modelled using high resolution aerial images (10-20 cm GSD) and photogrammetric DSM. Reliable models and algorithms for the estimation of the incoming sun radiance are then adopted and a WebGIS is set up for the interactive calculation of the photovoltaic (PV) potential in a raster-based form. The paper summarizes the entire pipeline and the results (Figure 1) achieved on the test areas to show the potentialities of the method and the web-based service.
\end{abstract}
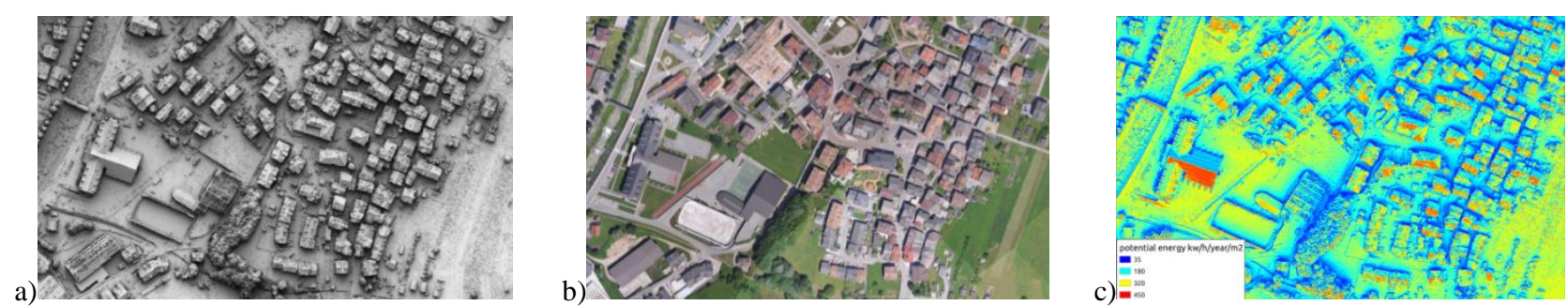

Figure 1. Results of the photogrammetric DSM generation from aerial images (a), true orthophoto (b) and solar potential energy estimation visualized with the raster-based webGIS tool created within the 3DSolarWeb project (c).

\section{INTRODUCTION}

Precise knowledge about photovoltaic (PV) potential and its spatial distribution in urban areas is playing a steadily growing role both for the public and private sector, due to its relevance for environmental and economic purposes. Solar technology is a valuable alternative for on-site clean energy production, as well as for the reduction of $\mathrm{CO}_{2}$ emissions. Moreover, the using building roofs to produce energy allows to save (or reduce) surfaces of land being converted from agricultural to PV plants. Public administrations, from national level down to the local one, need therefore to accurately assess questions about feasibility, convenience and durability of their policies, because of their ability to influence the market indirectly, by means of specific regulations, or directly, by economic subventions to install new PV panels. On the other hand, the private sector, from the energy companies down to the private end-user, can profit from better estimations of the photovoltaic potential in a given area or building, thus reducing the uncertainties of the initial investment.

As PV panels need to be properly located and oriented, an effective method of identifying suitable roof surfaces using reliable predictive models for solar radiance estimation is crucial. Evidence of the increasing interest for PV-market related services can be found in the following examples, with different applications developed to assist in the PV planning and yield estimation. Solar GIS services are provided for example by SOLEMI, PVGis or SoDa which can provide for large scale solar irradiance maps mostly everywhere on Earth, generally with very low raster resolution. Many cities worldwide (e.g. Berlin, Vienna, New York, San Francisco or Locarno, just to mention few of them) have created solar cadastre maps, often published and freely available on-line to enable the residents to look up their addresses and determine their buildings' potential for harnessing solar power (Figure 2).

The main drawback of these applications is that huge amounts of detailed and heterogeneous data are requested (ranging from meteorological data to multi-scale geometric models of the area). With regard to $3 \mathrm{D}$ data, on one hand, accurate and detailed models are requested to detect roof shadows in correspondence of chimneys and adjacent buildings. Unluckily, these data are rarely up-to-date, thus accurate 3D models (e.g. LoD2, see Kolbe, 2008) are not available in most of the cases, requiring new ad-hoc acquisitions. On the other hand, shadowing effects by nearby topography (mountains, forests, etc.) cannot be neglected (at least in mountainous regions). The solar radiation, then, must be validated using available solarimeters in the analysed area to check the quality of the 
achieved results. Finally, the solar cadastre must have a user friendly interface to be queried by municipalities and private users and provide quantitative estimation of each roof eligibility for energy production in a fast and easy way.

The paper presents the research work carried out in the 3DSolarWeb project to test and implement a complete pipeline (from data acquisition to data visualization and web-based publication) for a solar cadastre generation of building roofs located in alpine areas. The project aims at providing reliable results in a cost-effective way, using (low resolution) available data and new (possibly low-cost) aerial imagery acquisitions as input. FOSS (Free and Open Source Software) and automated or semi-automated procedures were preferred, to reduce the initial investments and the manual intervention in the PV estimation, respectively.

The 3DSolarWeb project deals primarily with PV estimation in Alpine regions, where most of the urban centres lie in valleys surrounded by mountains. While for cities located in "flat" regions one can consider only mutual shadowing by nearby objects and buildings, in case of mountainous regions, shadowing effects by nearby orography must be included in the estimation model of solar irradiance. The need of geometric accuracy and the variety of scales to be considered - from architectural to regional - has then obliged to consider a multiresolution approach: the environmental context is provided by already existing low resolution LiDAR data (1-2 m), while the urban area is modelled using high resolution images by means of a photogrammetric DSM (ca $20 \mathrm{~cm}$ ). In some existing solar cadastres, each building (and its roof facets) is described by means of vector-based prismatic models (e.g. as LoD2 models). Nevertheless LoD2 models do not consider the influence of little objects on the roofs such as chimneys, which may strongly influence the efficiency of solar panels. On the other hand, the use of LoD3 models is not yet an easy task, as such highly detailed models are extremely rare and their creation usually requests large amounts of manual works. For this reason, the use of raster images of high resolutions DSM was preferred in this project. The 3DSolarWeb project includes also a WebGIS for the interactive evaluation of PV potential using a true orthophoto as simple reference for the user to pan and search for houses.

\section{RELATED WORKS AND STATE OF THE ART}

In very general terms, scale represents an important factor, as availability and accuracy of existing geographical data plays a crucial role when selecting the spatial resolution of the results which are going to be produced. In the field of solar-related applications, examples of solar databases exist from continental level down to national, regional or city one, depending on the scope of the application (Bergamasco and Asinari, 2011; Ludwig et al. 2009; Izquierdo et al. 2008).
With particular attention to solar cadastres in urban contexts, a wide array of examples exist, as well as different approaches pursued at academic level or by private companies. Nevertheless, one common attribute is the quality and quantity of spatial data, more specifically the availability of accurate building models and other man-made features which could be used for PV production purposes. Nowadays very detailed and accurate 3D city models (Haala and Kada, 2010) are primarily created using very dense LiDAR data (Oude Elberink and Vosselmann, 2011; Jochem et al., 2011; Jochem et al. 2009; Kassner et al., 2008; Zhou and Neumann, 2008; Rottensteiner et al., 2005), although there is an increasing number of approaches based on dense image matching algorithms (Nex and Remondino, 2012; Zebedin, et al., 2006) and on the integration of different data sources (Vallet et al., 2011; Demir et al., 2009). Generally, each building (and its roof facets) is described as a closed set of vector surfaces. According to the level of detail (LoD), the buildings can be modelled as prismatic boxes (hence with flat roofs, at LoD1), or more conveniently with correctly oriented and inclined roof facets (at LoD2 or higher).

Regarding the tools for the estimation of the solar irradiance, nowadays several ones already exist, both in the commercial and open-source domain, such as for example Esri ArcGIS, Saga GIS or GRASS GIS. The different modules available in GRASS GIS are well-known and already tested in a variety of studies with reliable results (Kryza et al. 2010; Nguyen and Pearce, 2010; Hofierka and Kanuk 2009). Most of the approaches are based on 2.5D geometric models while Hofierka and Zlocha (2012) presented a new approach for 3D solar radiation model for urban areas represented by 3D building models (so including also vertical surfaces like facades).

When it comes to data publication and representation, heterogeneous approaches exist on how to publish data over the Internet. Results on roof eligibility can be published as raster layers (reclassified solar irradiance maps) on top of the building footprints (as well as with all ancillary maps: digital orthophotos, streets, etc.) in standard WebGIS platforms. If more detailed data are available, e.g. cadastral maps where even roof facets are represented, then an averaged global value for each roof facet is generally calculated and assigned to the corresponding vector feature. A proper colour coding can help the interpretation of the results (Figure 2).

\section{THE WORKFLOW}

The resulting pipeline of the 3DSolarWeb project is schematically presented in Figure 3, with the possible sources of data and the outcome named SolarWebGIS querying and visualisation tool (http://www.3dsolarweb.it/). The WebGIS aims to provide an easy-to-understand quantitative estimation of roofs' eligibility for PV production, both for the municipalities and the private end-users.
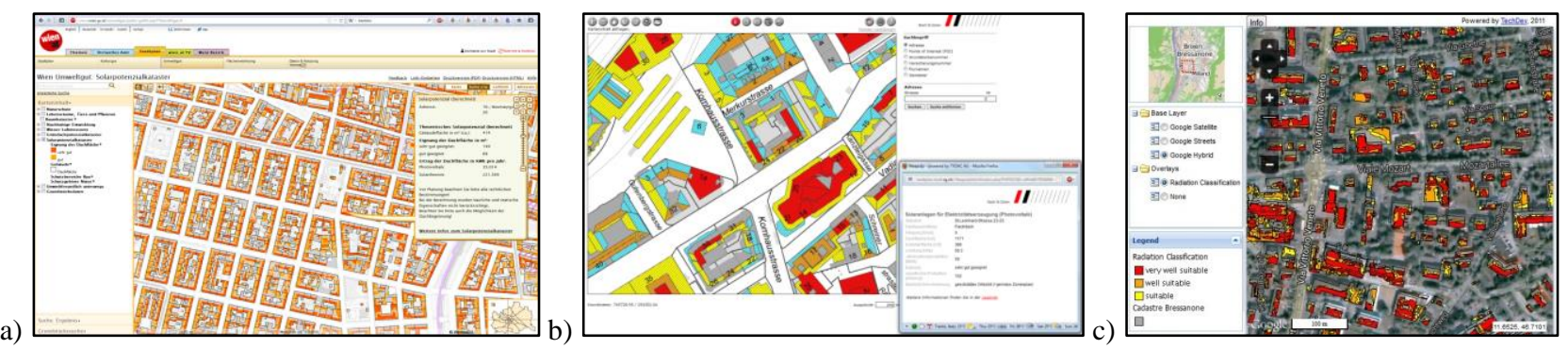

Figure 2: Examples of data representations by means of WebGIS for solar cadastres and photovoltaic potential of buildings: reclassified rasters of global solar irradiance overlaid to cadastral maps (Vienna - a), vector roof facets with assigned averaged values of incoming solar irradiance (St. Gallen - b), reclassified raster of PV potential overlaid on an orthoimage (Brixen $-\mathrm{c})$. 
Among the various case studies of the 3DSolarWeb project, the results achieved in the Transacqua town with its surrounding valleys (Province of Trento, northern Italy) will be presented and discussed throughout the paper to show the estimation methodology and the realized web-based visualization tool.

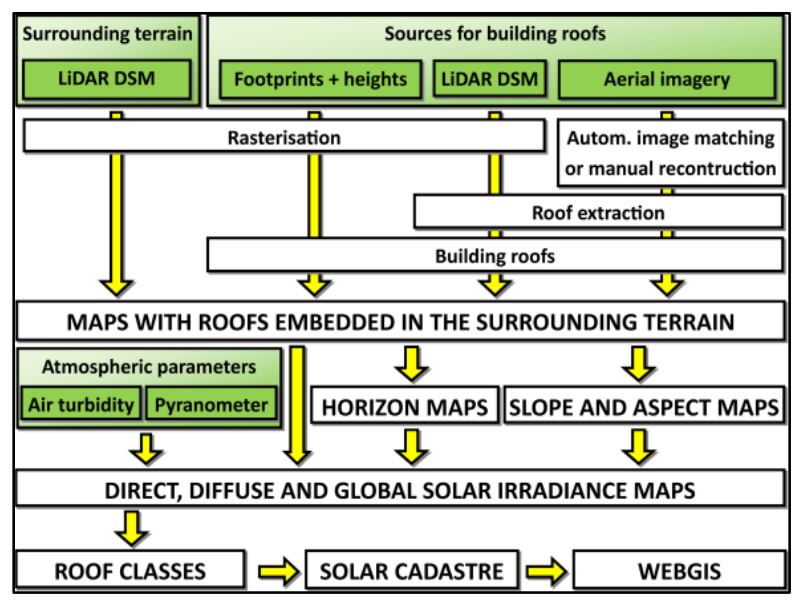

Figure 3: The pipeline of the 3DSolarWeb project for the precise estimation of the photovoltaic (PV) potential and its spatial distribution in (alpine) urban areas.

\subsection{Data acquisition and geo-information extraction}

Contrary to most of the published research works and available web-based systems, our methodology relies on LiDAR data (provided by the Autonomous Province of Trento) only for the environmental 3D reconstruction while it is based only on photogrammetric Digital Surface/Terrain Model (DSM/DTM) and roof models for the detailed PV potential estimation. Indeed image matching techniques can nowadays provide for dense and reliable point clouds, practically comparable to LiDAR ones in terms of accuracy and completeness. In theory, an image block with a GSD of $10 \mathrm{~cm}$ would allow the derivation of a point cloud with up to 100 points $/ \mathrm{m} 2$. A typical LiDAR flight for city-modeling applications is in the order of $15-20$ points $/ \mathrm{m} 2$, with much higher costs involved in the data acquisition and processing. The extraction of an higher number of object points allows to better define discontinuities and it is directly connected to the Level of Detail (LoD) that can be achieved in the geometric modelling. However, photogrammetric point clouds and DSM are usually noisier than LiDAR data as they suffers from the radiometric image quality, image overlap, presence of shadows, object texture, etc. A large image overlap can only partly improve the internal accuracy and the reliability of the results but several blunders can be still present in shadowed or almost occluded areas. But the higher number of details that can be detected (i.e. roof tiles) allows to better model surfaces (that are flat in lower resolution point clouds)
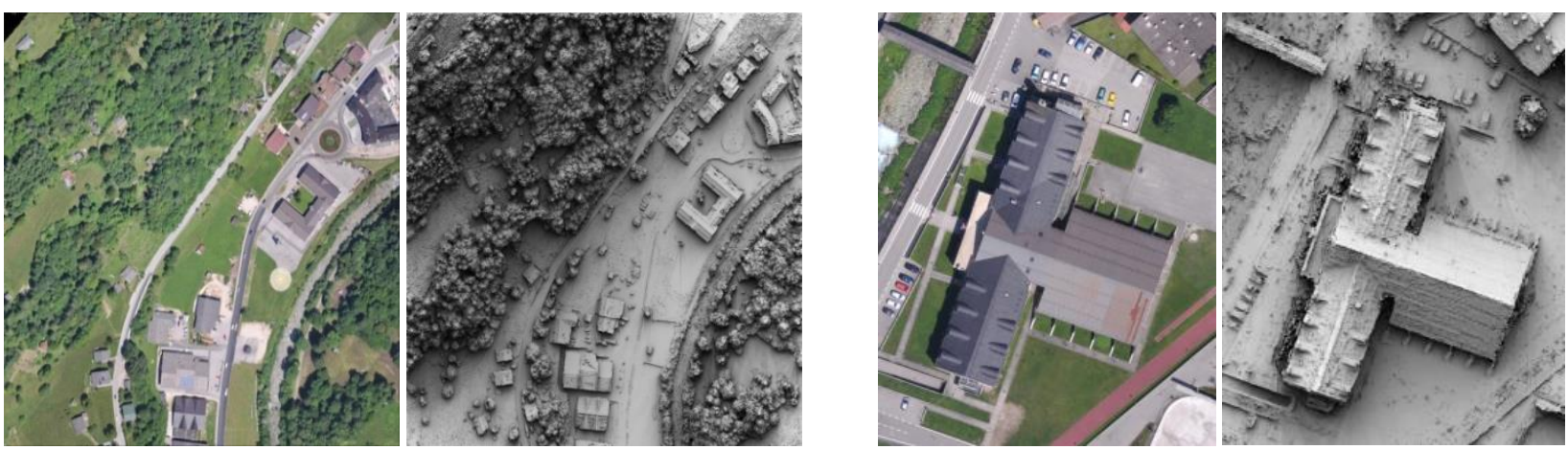

Figure 4: An example of the photogrammetric DSM (shaded view) over an alpine village (left) and a closer view of a building (right). even if this higher degree of detail can often interpreted as noise during the modelling.

The aerial images for the 3D reconstructions of the urban areas were acquired with an helicopter in order to have highly overlapping high resolution imagery $(9 \mathrm{~cm}$ GSD). After the image triangulation, for the dense point cloud and DSM generation, the Optimal Flow algorithm (Pierrot-Deseilligny and Paparoditis, 2006), implemented in the MicMac tool, is used. The matching uses a multi-scale, multi-resolution, pyramidal approach and derives a dense point cloud starting from some master images for the correlation procedure. Finally an energy minimization approach is applied to enforce surface regularities and avoid undesirable jumps. From the multi-stereo correlation results, depth maps are converted into metric 3D point clouds (Figure 4). For each 3D point a RGB attribute can be also assigned. From our experiences, a geometric resolution which is adequate to geometrically describe the house roofs is around $20 \mathrm{~cm}$, as such level of detail can assure the correct modelling of dormers, chimneys and ridges in order to estimate possible shadows and occlusions. Higher resolutions could deliver better results but they could negatively affect the computational time and the management of the final 3D data. Therefore some compromises must be established in terms of geometric resolution, computational time and irradiance calculation.

Once the matching algorithm has extracted a dense point cloud, a raster is produced for the successive roof extraction and PV estimation. Typical approaches and commercial solutions rely on building footprints in order to easily identify the roofs from the available DSM. In this work, to overcome the misalignment and distortion issues of existing vector datasets (Agugiaro et al., 2012), an automated method was develop in order to extract and separate footprints of adjacent buildings (Nex and Remondino, 2012). The method processes image-based point clouds in order to extract geometric primitives useful for a more complete and detailed reconstruction of roof buildings as well as footprint generation. The method is data-driven and it can analyse different typologies of buildings, but the results are strongly influenced by DSM quality which directly depends on the image quality.

\subsection{Solar radiation estimation}

PV systems, made up of one or more solar panels, convert sunlight into electricity. They need to be properly located and oriented in order to meet the required specifications (insolation time, surface orientation, panel type, characteristics of power network, etc.), therefore an effective and scientific method to identify suitable roof (or terrain, where permitted) surfaces and the adoption of reliable predictive models for solar irradiance estimation are crucial (Mueller et al., 2012; Blanc et al., 2011). 
The drawback is that huge amounts of heterogeneous data are required. They range from meteorological data (e.g. air turbidity, cloudiness, aerosol, water vapour, etc.) to accurate geometric models of the buildings and the nearby terrain (Ike and Kurokawa, 2005). The type of installed PV systems plays also an important role and for their installation, the knowledge of the direct, diffuse or global irradiation is needed. Conversion efficiencies typically range from $20 \%$ down to $7 \%$ of the incoming solar irradiance, depending on the adopted technology (Jacobsen, 2009; Ubertini and Desideri, 2003).

The solar radiation estimation was performed using the algorithms and modules available in GRASS GIS (http://grass.osgeo.org/). The estimation is realized implementing a Web Processing Service (WPS) that enables the user to calculate the photovoltaic potential of a surface via web, considering the angle of incidence of the sun with respect to geographical location the object, the occlusions at different times of the day and the turbidity of the air (Nguyen and Pearce, 2010). The algorithm was implemented in different steps:

(i) calculation of yearly shadowing maps for the different hours of the day;

(ii) calculation of the solar irradiation per hour through the year; (iii) combination of the solar irradiation with the air temperature and the type of photovoltaic system to estimate the energy production.

\subsubsection{Horizon computation}

Shading resulting from (terrain and buildings) occlusion are computed using the r.horizon module. The module requires as input a digital terrain model in raster format. The input dataset are normally a combination of high resolution Digital Surface Model (DSM) produced from airborne imagery (about $15-20 \mathrm{~cm}$ resolution) for the urban areas and a LiDAR-based DSM (provided by the Autonomous Province of Trento) at lower resolution (about 1-2 m) for the surrounding environment. For each pixel of the area of interest, the height of the horizon for an interval equal to 10 degrees is computed generating different horizon maps useful for the successive energy estimation.

\subsubsection{Calculation of the radiation}

The irradiation is calculated using the r.sun module. Specifically direct, diffuse and reflected radiation maps were derived in clear-sky conditions (Šúri and Hofierka, 2004). The global radiation was calculated for each pixel of the area of interest, at different times of the day and for each day of year. The calculation takes into account the angle of incidence of the solar trajectory, the height of the horizon and the turbidity of the air obtained from the dataset LINKE. The number of maps of irradiation time in the area of interest and amounted to 5475 with a size of $140 \mathrm{MB}$ on a map.

\subsubsection{Photovoltaic production estimation}

Starting from the maps of hourly radiation and air temperature, the solar electrical production estimation is then aggregated monthly and yearly. The calculation was performed by introducing a correction factor on the performance of the PV panel linked to the temperature of the cells. Using the "Practical guide to the preliminary sizing of a photovoltaic system" provided by Boso \& Partners Ltd., the hourly temperature of the cell was estimated starting from the air temperature according to the following:

$$
\mathrm{T}_{\mathrm{c}}=\mathrm{T}_{\mathrm{and}}+((\mathrm{NOCT}-20) / 800+0.015) \cdot \mathrm{G}
$$

where:

$\mathrm{T}_{\mathrm{c}}=$ cell temperature $\left[{ }^{\circ} \mathrm{C}\right]$;

$\mathrm{T}_{\text {and }}=$ hourly air temperature $\left[{ }^{\circ} \mathrm{C}\right]$;
NOCT $=$ cell rated operating temperature $\left[{ }^{\circ} \mathrm{C}\right]$;

$\mathrm{G}=$ irradiation time.

Starting from the temperature of the cell, the correction factor $\eta_{\text {temp }}$ on the standard performance was defined as:

$$
\eta_{\text {temp }}=(1-\gamma \cdot(\mathrm{Tc}-\mathrm{Tc}, \mathrm{std}))
$$

where:

$\gamma=$ coefficient of temperature, associated to the type of panel;

$\mathrm{T}_{\mathrm{c}, \mathrm{std}}=$ temperature of the cell under standard conditions.

From this, we can define the real production as:

$$
\eta_{\text {real }}=\eta_{\text {std }} \cdot \eta_{\text {temp }} \cdot \eta_{\text {plant }}
$$

where:

$\eta_{\text {std }}=$ production under standard conditions;

$\eta_{\text {plant }}=$ efficiency of the plant .

On the basis of the actual performance and of the estimated hourly irradiation, hourly maps of Electricity Produced Unit (EPU) where calculated as:

$$
\mathrm{EPU}=\mathrm{G} \cdot \eta_{\text {real }}
$$

Finally, the produced hourly maps of electrical energy unit are aggregated on a monthly and yearly basis.

In our implementation and computations, the standard panel is represented by a panel monocrystalline silicon with a yield of $16 \%$ in standard conditions, NOCT $48^{\circ} \mathrm{C}$ and $\gamma=0.40 \% /{ }^{\circ} \mathrm{C}$.

Other types of panels characterized by the type of cell can be implemented by varying the parameters related to the technical characteristics of the panel.

\subsubsection{Model Validation}

The validation is essential to define the reliability and performances of the implemented model and to evaluate the use of other possible variables to improve the estimation of the PV production. The data used to validate the implemented model are real production data collected from a production plant with the following characteristics: 252 panels (SHARP 245) covering an area of $416 \mathrm{~m}^{2}$, each panel is polysilicon with a dimension of $156.5 \mathrm{~mm} \times 156.5 \mathrm{~mm}$ and 60 cells in series. The panels are located on roof pitches with an inclination of 18 degrees and about 5 degrees west orientation. It is important to specify that the data used for validation refer to a year of daily production therefore only a partial validation of the model was possible. Giving the production model estimated in clear sky conditions, the validation did not consider days with low pressure (values below 940 mbar) and when rainfall was recorded - the closest weather station is $1,5 \mathrm{~km}$ away from the plant. Those production records that indicated a production much lower than the figures recorded in a time window of 5 days were filtered too. The model was validated using a daily time series of 88 points (Figure 5) where the absolute value of difference between the production estimated from the model and the daily production record from the plant was calculated. Excluding the month of April, the average difference ranges between 8.25 and 33.92 KWh (Table 1). Most probably in April some problems have occurred to the plant - as shown in Figure 5 the daily production was close to 0 and no rain or low air pressure was recorded at the weather station.

\begin{tabular}{|c|c|c|c|c|c|c|c|c|c|c|c|c|}
\hline & Jan & Feb & Mar & Apr & May & Jun & Jul & Aug & Sept & Oct & Nov & Dic \\
\hline \#Points & 8 & 0 & 2 & 8 & 2 & 5 & 7 & 12 & 11 & 12 & 11 & 10 \\
\hline Emor [KWh] & 38.42 & - & 9.77 & 259.77 & 3.63 & 8.25 & 20.15 & 12.98 & 13.58 & 12.76 & 12.84 & 33.92 \\
\hline
\end{tabular}

Table 1: Average production error and number of points aggregated on a monthly time scale. 


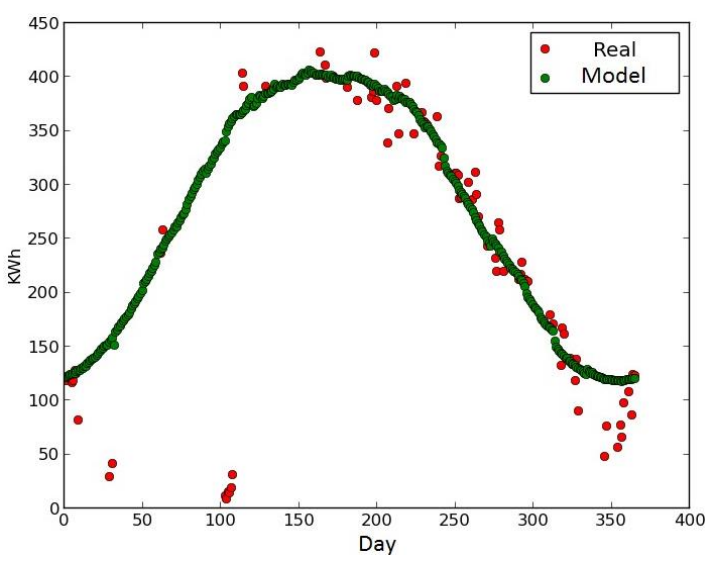

Figure 5: Estimated and real (measured) energy production on the plant used for the model validation.

\subsection{WebGIS implementation}

A pilot WebGIS interface has been developed implementing the basic functionalities of the planned conclusive version (Figure 6 ). The final aim of the geo-web platform is to give to the end user an opportunity to evaluate the possible installation of photovoltaic panels on his own roof, taking into account the costs in relation with the estimated energy production of the different roof sections. Thus far, the basic set of realised functionalities allows to navigate among different thematic maps (true orthophoto, roof's pitches boundaries and EPU) and to visualize the trend of the mean estimated energy production in a specific point of the roof (Figure 6). The WebGIS platform is composed of an advanced Open Source WPS server (framework PyWps) for on-the-fly calculation of solar irradiance/photovoltaic potential and of an Open Source cartographic WebGIS server for map publication and user's authentication (based on MapServer and a Django framework implementation). In particular, the process allows to obtain values of solar radiation and solar electrical production monthly and annually on a surface which is identified by the user in the web interface. After the identification of a surface of interest (e.g. a pitch of a roof), the web tool yields the values of energy production for the identified polygon.

\section{CONCLUSIONS AND FUTURE DEVELOPMENTS}

The article reports the whole pipeline required to create a webbased solar cadastre for photovoltaic (PV) potential in a complex Alpine landscape. Given the complexity of the whole sun-to-electricity pipeline, a multidisciplinary approach has been adopted. Using already existing and (mostly) publicly available data, with few new acquisitions, highly detailed geometric 3D data of building roofs are generated by means of dense image matching methods. These data are used, in combination with other raster and vector data sources, to estimate the incoming solar irradiance hitting the roofs. Atmospheric effects, geographical site position and elevation, terrain characteristics, as well as shadowing by chimneys, dormers, nearby buildings, vegetation and terrain are taken into account. The validated methodology delivered satisfactory results in the test areas and allowed to create a solar cadastre PV potential assessment on building roofs. Results are presented by means of a WebGIS platform for public access.

The developed pipeline is based upon free and open-source software, from the DSM and roof geometric model generation to the solar analyses, data repository, results visualisation and publication.

The geometric resolution (about $20 \mathrm{~cm}$ ) of the created DSM over the urban areas was a good compromises considering geometric details, computational time and irradiance calculation.

The web-based data publication tool enables non-expert endusers to evaluate the suitability of their roofs for PV installations. A standard 2D view is offered, although in the near future a 3D view inside the web browser will be added. Future developments of the web interface will also allow to place different types of photovoltaic panels on the roofs, automatically taking into account the roof slope (i.e. shaping the panel footprint according to the slope) as well as avoiding roof pitches and substructure (e.g. chimneys and dormer windows). The final version will allow citizens to evaluate the suitability of entire roofs (or roof portions) for PV panel installation and technicians (surveyors, architects, engineers) to compare costs and energy production of a single installation, by determining in a very precise way, among other quantities, the time needed for investment's return (based on Energy Returned on Money Invested).

\section{REFERENCES}

Agugiaro, G., Nex, F., Remondino, F., De Filippi, R., Droghetti, S., Furlanello, C., 2012: Solar radiation estimation on building roofs and web-based solar cadastre. ISPRS Annals of the Photogrammetry, Remote Sensing and Spatial Information Sciences, Vol. I(2), pp. 177-182.
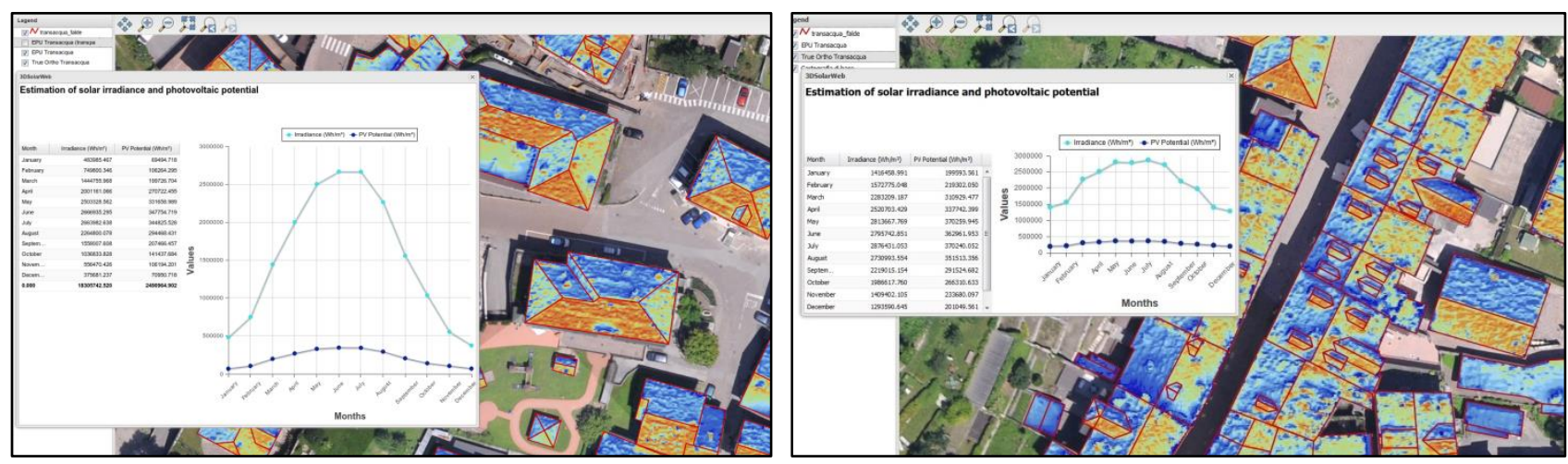

Figure 6: Example of the color coding web-based visualization of the estimated pixel-based solar irradiance and PV potential. The extracted building roof outlines are visualized on the true orthoimage. Clicking on a building pitch's roof, the estimated irradiation and EPU curves are shown. 
Bergamasco, L., Asinari, P., 2011: Scalable methodology for the photovoltaic solar energy potential assessment based on available roof surface area: Application to Piedmont Region (Italy). Solar Energy, Vol. 85(5), pp. 1041-1055.

Blanc, P., Gschwind, B., Lefèvre, M., Wald, L., 2011: The HelioClim project: surface solar irradiance data for climate applications. Remote Sensing, Vol. 3, pp. 343-361.

Demir, N., Poli, D., Baltsavias, E., 2009: Detection of buildings at airport sites using images \& LiDAR data and a combination of various methods. ISPRS Int. Archives of Photogrammetry and Remote Sensing and Spatial Information Sciences, Vol. 38(3/W4), pp. 71-77.

Haala, N., Kada, M., 2010: An update on automatic 3D building reconstruction. ISPRS Journal of Photogrammetry and Remote Sensing, Vol. 65, pp. 570-580.

Hofierka, J., Kaňuk, J., 2009: Assessment of photovoltaic potential in urban areas using open-source solar radiation tools. Renewable Energy, Vol. 34(10), pp. 2206-2214.

Hofierka, J., Zlocha, M., 2012: A new 3-D solar radiation model for 3-D city models. Transactions in GIS, Vol. 16, pp. 681-690.

Ike, S., Kurokawa, K., 2005: Photogrammetric estimation of shading impacts on photovoltaic systems. Proc. $31^{\text {st }}$ Photovoltaic Specialists Conference, IEEE, pp. 1796-1799.

Izquierdo, S., Rodrigues, M., Fueyo, N., 2008: A method for estimating the geographical distribution of the available roof surface area for large-scale photovoltaic energy-potential evaluations. Solar Energy, Vol. 82(10), pp. 929-939.

Jacobson, M.Z., 2009: Review of solutions to global warming, air pollution and energy security. Energy \& Environmental Science, Vol. 2, pp. 148-173.

Jochem, A., Hofle, B., Rutzinger, M., Pfeifer, N., 2009: Automatic roof plane detection and analysis in airborne Lidar point clouds for solar potential assessment. Sensors, Vol. 9, pp. 5241-5262, doi:10.3390/s90705241.

Jochem, A., Höfle, B., Hollaus, M., Rutzinger, M., 2009: Object detection in airborne LIDAR data for improved solar radiation modeling in urban areas. ISPRS Int. Archives of Photogrammetry and Remote Sensing and Spatial Information Sciences, Vol. 38(3/W8), pp. 1-6.

Kassner, R., Koppe, W., Schüttenberg, T., Bareth, G., 2008: Analysis of the solar potential of roofs by using official LiDAR data. ISPRS Int. Archives of Photogrammetry and Remote Sensing and Spatial Information Sciences, Vol.37(4).

Kolbe, T., Groeger, G., Pluemer, L., 2008: CityGML - 3D City models for emergency response. In: Zlatanova/ Li (Eds): GeoInformation technology for emergency response, pp. 257-274.

Kryza, M., Szymanowski, M., Migala, K., Pietras, M., 2010: Spatial information on total solar radiation: Application and evaluation of the r.sun model for the Wedel Jarlsberg Land, Svalbard. - Polish Polar Research, Vol. 31(1), pp. 17-32.

Ludwig, D., Lanig, S., Kärle, M., 2009: Location analysis for solar panels by LiDAR-data with geoprocessing - SUN-AREA.
Envi-roinfo 2009, Proc. $23^{\text {rd }}$ Int. Conference on Informatics for Environmental Protection, Berlin, Germany.

Mueller, R., Behrendt, T., Hammer, A., Kemper, A., 2012: A new algorithm for the satellite-based retrieval of solar surface irradiance in spectral bands. Remote Sensing, Vol. (4), pp. 622647.

Nex, F., Remondino, F., 2012: Automatic roof reconstruction from photogrammetric DSM. ISPRS Annals of Photogrammetry, Remote Sensing and Spatial Information Sciences, Vol.(I-3), pp. 257-262.

Nguyen, H.T., Pearce, J.M., 2010: Estimating potential photovoltaic yield with r.sun and the open source Geographical Resources Analysis Support System. Solar Energy, Vol. 84(5).

Oude Elberink, S., Vosselmann, G., 2011: Quality analysis on 3D building models reconstructed from airborne laser scanning data. ISPRS Journal of Photogrammetry and Remote Sensing, Vol. 66(2), pp. 157-165.

Pierrot-Deseilligny, M., Paparoditis, N., 2006: A multiresolution and optimization-based image matching approach: An application to surface reconstruction from Spot5HRS stereo imagery. ISPRS Int. Archives of Photogrammetry, Remote Sensing and Spatial Information Sciences, Vol. 36(1/W41).

Rottensteiner, F. Trinder, J., Clode, S., Kubik, K., 2005: Automated delineation of roof planes from LiDAR data. Int. Archives of Photogrammetry and Remote Sensing and Spatial Information Sciences, Vol. 36(3/W19), pp. 221-226.

Šúri, M., Hofierka, J., 2004: A New GIS-based solar radiation model and its application to photovoltaic assessments. Transactions in GIS, Vol. 8, pp. 175-190.

Ubertini, S., Desideri, U., 2003: Performance estimation and experimental measurements of a photovoltaic roof. Renewable Energy, Vol. 28, pp. 1833-1850.

Vallet, B., Pierrot-Deseilligny, M., Boldo, D., Brédif, M., 2011: Building footprint database improvement for 3D reconstruction: A split and merge approach and its evaluation. ISPRS Journal of Photogrammetry and Remote Sensing, Vol. 66(5), pp. 732-742.

Zebedin, L., Klaus, A., Gruber-Geymayer, B., Karner, K., 2006: Towards 3D map generation from digital aerial images. ISPRS Journal of Photogrammetry \& Remote Sensing, Vol. 60(6), pp. 413-427.

Zhou Q.-Y., Neumann, U., 2008: Fast and extensible building modeling from airborne LiDAR data. ACM GIS.

\section{ACKNOWLEDGEMENTS}

The work was partly supported by the European Regional Development Fund, the Legge6/1999 of the Autonomous Province of Trento (Italy) and by the CIEM and $3 \mathrm{M}$ projects (co-founded Marie-Curie Actions FP7 - PCOFOUND - GA2008-226070, acronym "Trentino Project" and "Incoming Team 2009"). The authors would also like to thank the Autonomous Province of Trento and the Municipality of Trento, which kindly provided most of the spatial geo-data. 